TAO, Vol. 17, No. 1, 91-109, March 2006

\title{
Rainfall Estimation of Mesoscale Convective System Using AMSU-A Data During the Mei-Yu Season
}

\author{
Jen-Chi Hu ${ }^{1}{ }^{1}$, Wann-Jin Chen ${ }^{1}$, Ching-Chung $\mathrm{Li}^{1}$ and Chun-Chieh Chao ${ }^{2}$
}

(Manuscript received 7 April 2003, in final form 15 January 2004)

\begin{abstract}
This study aims to obtain the rate of rainfall (RR) over ocean areas using satellite data by establishing the relationship between Advanced Microwave Sounding Unit-A (AMSU-A) microwave brightness temperature (Tbs) data and island rain gauge rainfall. This study applied a rain identification technique developed by Grody et al. (1999) using AMSU-A data accepted to screen rain events over ocean areas. Using rain gauge data of Sakishima-shoto in Japan as a ground truth, validation of rain identification was conducted every May and June from 1999 to 2001. Including times of both rainfall and no rainfall, the overall rates of successful recognition were $87.3 \%, 87 \%$, and $89 \%$ for 1999,2000 , and 2001, respectively. As for quantitative validation, the coefficient of determination was 0.72 . To obtain further precipitation observations, another rainfall estimation retrieved by the TRMM Microwave Imager (TMI) data onboard the Tropical Rainfall Measuring Mission (TRMM) was compared with the AMSU-A data. The results displayed solid agreement in rainfall patterns and rain distribution. Additionally, when the AMSU-A RRs were multiplied by a factor of approximately 1.5 (particularly for heavy rainfalls), the intensities of the AMSU-A RRs roughly equaled those of the TMI RRs. Combining this data with the other satellite rainfall retrieval data, a series of AMSUA rain maps for sea areas were shown to mitigate the problem of relatively sporadic observations of rainfall at sea.
\end{abstract}

(Key words: Quantitative precipitation, Rainfall rate, Microwave channels, AMSU-A)

${ }^{1}$ Chung Cheng Institute of Technology, National Defense University, Taoyuan, Taiwan, ROC

2 Chinese Air Force Meteorological Center, Taipei, Taiwan, ROC

* Corresponding author address: Mr. Jen-Chi Hu, Chung Cheng Institute of Technology, National Defense University, Taoyuan, Taiwan, ROC; E-mail: g970101@ccit.edu.tw 


\section{INTRODUCTION}

During the Mei-Yu season (from May to June) numerous disasters, such as flash floods and mudslides, occur in Taiwan owing to heavy rainfall induced from Mesoscale Convective Systems (MCSs) from the ocean. Unfortunately, information on rainfall caused by MCSs is scarce due to a lack of sea-based meteorological radar and rain gauges. Therefore, other methods for estimating the rainfall rate over sea areas accurately are urgently required to reduce losses from heavy rainfall associated with MCSs.

Satellite rainfall retrieval can provide rainfall estimates more frequently and over a wider area than conventional direct rain gauge measurements; they thus can be useful in detecting heavy rain events caused by MCSs. Infrared (IR) radiometers on satellites sense radiation emitted from cloud-tops. IR observations thus cannot provide information on the vertical structure of clouds, or on near-surface rain layers. Moreover, satellite visible (VIS) data are only available in the daytime, limiting the potential for improving some IR rainfall algorithms. However, passive microwave (MW) radiometers can physically sense drops and hydrometeors within precipitating clouds. MW rainfall retrieval methods use more direct measurements than IR rainfall retrievals, and MW rain estimates generally are more accurate than IR estimates. Therefore, MW rain estimates are widely used in both flash flood monitoring and oceanic heavy rainfall warnings.

As a polar molecule, water has a very large dielectric constant at microwave frequencies. This property accounts for the high reflectivity (low emissivity) of the ocean surface (Wilheit and Chang 1980). The low emissivity of the ocean surface provides a good cold background for viewing particles with relatively higher emissivities, such as rain, over the ocean. Consequently, emission rainfall algorithms rely upon the amount of extra radiation emitted by the precipitation particles against a radiometrically cold background - namely, the ocean - for retrieving rain rates (RRs). In contrast, land surfaces have emissivities in the range of 0.8 0.95 range, and thus emission rainfall algorithms are unsuitable for overland applications, because the high surface emissions effectively mask the precipitation attenuation. On the other hand, scattering rainfall algorithms rely on the general cooling in the high-frequency channels due to the scattering by ice in the upper portions of many raining clouds.

Establishing the relationship between the increased MW Tbs and hourly RRs for emission rainfall algorithms, or between decreased Tbs and RRs for scattering rainfall algorithms, require utilizing a theoretically derived relationship between Tbs and RRs or applying regression techniques to ground-truth data. Island rain gauge data can be used as ground-truth data coincident with satellite rainfall observations (Chen and Li 2000). Rainfall observations were treated as representing the rainfall for the waters around the island (or island gauge). MW data from the AMSU-A onboard the NOAA satellites were used in this study to estimate oceanic RRs. Using multi-channel MW Tbs from the AMSU-A and rainfall observations from island gauges near Taiwan, this study used a piecewise linear regression technique introduced by Chen and $\mathrm{Li}$ (2002a) to establish Tbs-RR linear regression equations. This study develops an AMSU-A rainfall algorithm for estimating oceanic RRs using the AMSU-A. 


\section{DATA}

The study domain ranged from $15^{\circ} \mathrm{N}, 110^{\circ} \mathrm{E}$ to $30^{\circ} \mathrm{N}, 130^{\circ} \mathrm{E}$. This study used four data sets during the 1999 to 2001 Mei-Yu season: (1) AMSU-A passive microwave measurements/ NOAA-15, -16, (2) IR measurements from the AVHRR (Advanced Very High Resolution Radiometer)/NOAA-15, -16, (3) IR measurements from the VISSR (Visible and Infrared Spin Scan Radiometer)/GMS (Geostationary Meteorological Satellite)-5, and (4) rainfall accumulation $(\mathrm{mm})$ over one hour from island rain gauges. These data were obtained from nine different islands in Japan, and were provided by the Japan Meteorological Agency (JMA). Moreover, the AMSU-A and AVHRR satellite data come from NOAA/NESDIS (National Oceanic and Atmospheric Administration/National Environmental Satellite, Data, Information Service), and the GMS-5 data come from the Central Weather Bureau of Taiwan.

The AMSU-A is a 15-channel temperature sounder that operates at frequencies from 23.8 to $89.0 \mathrm{GHz}$. All AMSU-A channels have a fine resolution of $48 \mathrm{~km}$ (compared to $110 \mathrm{~km}$ for the MSU) at their nadir with window channels at 23.8, 31.4 and $89.0 \mathrm{GHz}$, representing the primary channels used to retrieve oceanic RR. The AMSU-A has an instantaneous field of view (FOV) of $3.3^{\circ}$ at the half-power point, providing a cross-track, scanning $+48.33^{\circ}\left(-48.33^{\circ}\right)$ from the nadir with a total of $30 \mathrm{FOV}$ (as opposed to 11 for the MSU) per scan line, and completes one scan every eight seconds.

AVHRR data were used to avoid the beam-filling problem (Kummerow 1998) by discarding inhomogeneous precipitating AMSU-A pixels. Since the AMSU-A and AVHRR were both on the same satellite, no time difference existed between them. Additionally, the horizontal spatial resolution of AVHRR pixel is much better than that of AMSU-A. Accordingly, sufficient AVHRR pixels exist within the footprint of an AMSU-A pixel to distinguish the homogeneous and inhomogeneous field of view. In this study, the AVHRR pixels were superimposed on the footprint of AMSU-A pixel and a supervised classification method was used (Richards and Jia 1999) to identify the weather conditions (raining or nonraining) by monitoring the AVHRR IR image pattern (cloud distribution) within an AMSU-A raining pixel. This is a very important procedure for verifying whether the rain gauge was located on the edge of a cumulonimbus cloud. If the rain gauge was so located, the beam-filling problem could be said to have occurred, and the RR retrieval result would be left uncorrected.

The GMS-5 satellite was launched in March 1995 into geostationary orbit at a height of $36000 \mathrm{~km}$, located at nominal geodetic coordinates of $0^{\circ} \mathrm{N}$ and $140^{\circ} \mathrm{E}$. The positioning of the satellite at $140^{\circ} \mathrm{E}$ provides it with an excellent view of the Western Pacific regions, as well as the whole of continental Australia. Full disk images are relayed to ground receiving stations approximately 25 - 28 times per day, with half-hourly coverage during some periods of the day. The VISSR onboard the GMS-5 satellite can provide IR data with a spatial resolution of $5 \mathrm{~km}$ (at the nadir) at the 6.7-, 11- and 12-micron bands. Two thermal IR channels are located within the atmospheric window $(8-14 \mu \mathrm{m}) .11-\mu \mathrm{m}$ data were used to monitor MCS intensity (GMS-5 User's Guide 1997).

The JMA provided oceanic rainfall data from nine islands (Table 1) in the study domain during the 1999 - 2001 Mei-Yu season including: MIYAKOJIMA (station \#93041), TARAMA (\#93061), IBARUMA (\#94001), YONAGUNIJIMA (\#94017), KABIRA (\#94036), 
Table 1. Locations of island rain gauge stations in Japan and Taiwan.

\begin{tabular}{|c|c|rc|c|}
\hline Rain Gauge Station & Code of Station & North Lat. & East Lon. & Altitude $(\mathrm{m})$ \\
\hline MIYAKOJIMA & 93041 & $24.79 \mathrm{~N}$ & $125.28 \mathrm{E}$ & 40 \\
\hline TARAMA & 93061 & $24.67 \mathrm{~N}$ & $124.70 \mathrm{E}$ & 16 \\
\hline IBARUMA & 94001 & $24.50 \mathrm{~N}$ & $124.28 \mathrm{E}$ & 15 \\
\hline YONAGUNIJIMA & 94017 & $24.46 \mathrm{~N}$ & $123.01 \mathrm{E}$ & 30 \\
\hline KABIRA & 94036 & $24.46 \mathrm{~N}$ & $124.14 \mathrm{E}$ & 7 \\
\hline ISHIGAKIJIMA & 94081 & $24.33 \mathrm{~N}$ & $124.16 \mathrm{E}$ & 6 \\
\hline IRIOMOTEJIMA & 94061 & $24.39 \mathrm{~N}$ & $123.75 \mathrm{E}$ & 9 \\
\hline OOHARA & 94101 & $24.26 \mathrm{~N}$ & $123.87 \mathrm{E}$ & 28 \\
\hline HATERUMA & 94116 & $24.05 \mathrm{~N}$ & $123.76 \mathrm{E}$ & 32 \\
\hline PENGCHIAYU & 46695 & $25.62 \mathrm{~N}$ & $122.07 \mathrm{E}$ & 101 \\
\hline LUTAO & 46780 & $22.65 \mathrm{~N}$ & $121.47 \mathrm{E}$ & 281 \\
\hline LANYU & 46762 & $22.04 \mathrm{~N}$ & $121.55 \mathrm{E}$ & 324 \\
\hline
\end{tabular}

IRIOMOTELIMA (\#94061), ISHIGAKIJIMA (\#94081), OHARA (\#94101), and HATERUMA (\#94116). The data time step was 10 minutes. The Central Weather Bureau (CWB) of Taiwan also provided hourly rain measurements from three islands: Pengchiayu $\left(25.62^{\circ} \mathrm{N}, 122.07^{\circ} \mathrm{E}\right)$, Lutao $\left(22.65^{\circ} \mathrm{N}, 121.47^{\circ} \mathrm{E}\right)$, and Lanyu $\left(22.04^{\circ} \mathrm{N}, 121.55^{\circ} \mathrm{E}\right)$. Rain gauge data from these islands were treated as ground truth data, and were used to establish linear regression equations between the island RRs and coinciding AMSU-A MW Tbs.

\section{AMSU-A RAINFALL RETRIEVAL ALGORITHM}

The radiative transfer processes of rain can be separated into two regimes: the attenuation and scattering regimes. The microwave Tbs observed in the attenuation regimes represent observations of the liquid hydrometeors within the raining cloud, which can be considered direct rainfall measurements. On the other hand, the microwave Tbs observed in the scattering regime depends on the many details of the ice layer. The satellite microwave Tbs thus can be divided into attenuation-based and scattering-based measurements. The factors determining the type of attenuation encountered include precipitation particle size, particle phase (ice or liquid), and the radiation wavelength (Chen and Li 2002a). This study considered the limbcorrected and the asymmetry correction problem (Weng et al. 2003) of the AMSU-A data by discarding the furthest three pixels on each scanning side. Since the value of the scanning view 
angle might not be the same for all AMSU-A raining pixels, and since little water vapor exists in the path from the cloud-top to the satellites, a slight difference is caused by the attenuation of water vapor above the top of the raining cloud to the radiometer of the satellite.

The rain threshold for the AMSU-A channel was determined using the AMSU-A Tb statistic of demonstrating no rain events from island stations. In this study, the rain thresholds are taken as the mean values of the Tb. Table 2 shows the rain thresholds for five rain gauge stations in 1999 - 2001. These thresholds were 208.37, 179.42, and 254.56 K for the Tb23,

Table 2. Rain thresholds for the Tb23, Tb31 and Tb89 (corresponding to AMSUA channels \#1, 2 and 15). Tbs \pm Std, Tbs: brightness temperatures, Std: standard difference.

\begin{tabular}{llllll} 
Year & $\begin{array}{l}\text { Rain Gauge } \\
\text { Station } \\
93041\end{array}$ & Tb23.8(GHz) & Tb31.4(GHz) & Tb89(GHz) & $\begin{array}{l}\text { Number } \\
\text { of Pixels }\end{array}$ \\
\hline 1999 & $207.84 \pm 14.09$ & $178.72 \pm 9.10$ & $254.73 \pm 11.25$ & 41 \\
2000 & $203.85 \pm 18.01$ & $177.77 \pm 12.39$ & $251.33 \pm 16.20$ & 43 \\
2001 & $213.43 \pm 12.70$ & $182.31 \pm 11.09$ & $257.64 \pm 9.28$ & 46 \\
\hline Average & $208.37 \pm 14.93$ & $179.60 \pm 10.86$ & $254.56 \pm 12.24$ & \\
\hline & 93061 & & & & 41 \\
1999 & $210.20 \pm 14.16$ & $180.99 \pm 12.23$ & $257.07 \pm 10.96$ & 41 \\
2000 & $205.33 \pm 17.99$ & $178.23 \pm 11.87$ & $252.91 \pm 15.56$ & 40 \\
2001 & $211.95 \pm 14.69$ & $180.95 \pm 15.42$ & $256.37 \pm 10.51$ & 45 \\
\hline Average & $209.16 \pm 15.61$ & $180.05 \pm 13.17$ & $255.45 \pm 12.34$ & \\
\hline & & & & 4 \\
1999 & 94017 & & & & 4 \\
2000 & $211.79 \pm 14.35$ & $181.62 \pm 12.52$ & $258.09 \pm 10.93$ & 44 \\
2001 & $204.31 \pm 15.79$ & $176.60 \pm 12.11$ & $252.04 \pm 12.76$ & 45 \\
\hline Average & $212.73 \pm 11.14$ & $180.06 \pm 9.68$ & $259.56 \pm 8.42$ & 34 \\
\hline
\end{tabular}


$\mathrm{Tb} 31$, and $\mathrm{Tb} 89$ respectively. Island rain gauge data can be used as ground-truth data coincident with the satellite rainfall observations (Chen and Li 2000). In this study, rain gauge observations were treated as the rain representatives for the waters around the associated island. Because the island area is smaller than AMSU-A FOV, this study does not consider the island land effect on rainfall retrieval.

\subsection{Rain Identification}

Figure 1 illustrates a flowchart of the rainfall retrieval algorithm, showing the procedure used to identify a raining pixel and recognize its rain type. The rainfall retrieval is processed if an AMSU-A measurement is recognized as a rain event. This study made rain type classifications using a threshold check (TC) technique (Chen and Li 2002b). Raining AMSU-A measurements with $\mathrm{Tb} 89$ lower than their threshold are classified as rain events associated with an emission-based mechanism. Other cases are considered a rain event associated with the scattering-based mechanism.

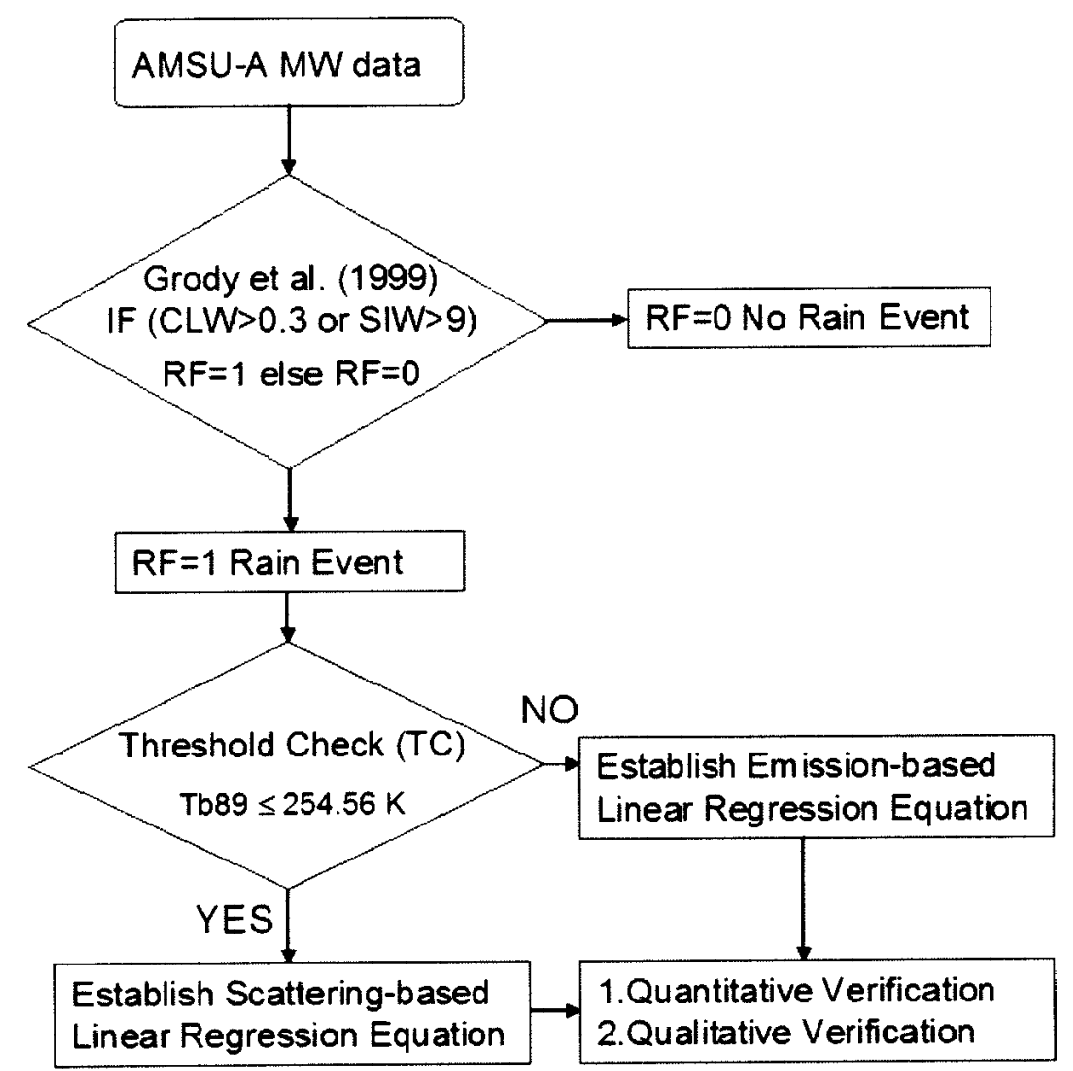

Fig.1. The flowchart of the rainfall retrieval algorithm. 
Rainfall retrieval comprises four main steps: step 1 is rain identification, which involves separating the input AMSU-A data into raining and nonraining pixels; step 2 is rainfall estimation, which involves two algorithms for emission- and scattering-based rainfall retrieval mechanisms; step 3 is a quantitative verification procedure, in which the ground truth was used to verify rain estimation, and step 4 is the qualitative verification. Oceanic rain region distribution is compared with various satellite IR images. Accurate rain identification determines the efficiency of rainfall retrieval using satellite-based passive microwave radiometers. Any rain identification technique must focus on accurately distinguishing rain signals from environmental noise.

The rain flag (RF) rain identification technique presented by Grody et al. (1999) was employed to screen raining regions over the ocean. A parameter called Cloud Liquid Water (CLW) was defined for weather classification, and is shown in equation (1):

$$
\begin{aligned}
& \mathrm{CLW}=\operatorname{Cos} \mathrm{Z} \times[\mathrm{A}+\mathrm{B} \times \log (285-\mathrm{Tb} 23)+\mathrm{C} \times \log (285-\mathrm{Tb} 31)], \\
& \mathrm{A}=8.24-(2.622-1.846 \times \operatorname{Cos} \mathrm{Z}) \times \operatorname{Cos} \mathrm{Z}, \\
& \mathrm{B}=0.754, \\
& \mathrm{C}=-2.265,
\end{aligned}
$$

where $\mathrm{Z}$ denoted the zenith angle. According to the thresholds for CLW, all AMSU-A measurements were separated into one of the two rain flag (RF) categories: raining (CLW >0.3) and nonraining ( $C L W \leq 0.3)$, represented by RF values of 1 and 0 respectively.

According to the scattering characteristics of Channel 15 of the AMSU-A at $89.0 \mathrm{GHz}$, Grody et al. also introduced another parameter - Scattering Index over Water (SIW) - in order to screen oceanic raining regions. This parameter is shown as equation (2):

$$
\mathrm{SIW}=-113.2+(2.41-0.0049 \times \mathrm{Tb} 23) \times \mathrm{Tb} 23+0.454 \times \mathrm{Tb} 31-\mathrm{Tb} 89 .
$$

According to the thresholds for SIW, all AMSU-A measurements were separated into one of the two rain flag (RF) categories: raining (SIW > 9) and nonraining (SIW $\leq 9$ ), which were represented by RF values of 1 and 0 respectively.

By using rain gauge data from Sakishima-shoto of Japan as the ground truth, rain identification validation was carried out using both the TC and RF techniques in both May and June of the years 1999, 2000, and 2001. They display the comparison with the RF and TC techniques in 1999, 2000, and 2001, respectively (Tables 3, 4, and 5). The statistics for using the $\mathrm{RF}$ technique to identify rain and no rain events are better than those obtained using the TC technique, and the successful recognition rates using the RF technique are $87.3 \%, 87 \%$, and $89 \%$ for 1999,2000 , and 2001 respectively.

The next step after recognizing oceanic rain regions is to classify their rain types. Rain type classifications were made using the TC technique. The threshold of $89.0 \mathrm{GHz}$ of the AMSU-A channel was used to classify the rain types, with those under $254.56 \mathrm{~K}$ being classified as scattering-based mechanisms, while those over $254.56 \mathrm{~K}$ were classified as emissionbased mechanisms. 
Table 3. Rain identification statistics obtained using the RF and TC techniques in 1999.

\begin{tabular}{lcccccccc}
\hline & Overall & \multicolumn{3}{c}{17 Rain Events } & \multicolumn{3}{c}{212 No Rain Events } \\
& SIR & Rain & No Rain & SIR & Rain & No Rain & SIR \\
Rain Flag (Grody) & $87.3 \%$ & 16 & 1 & $94 \%$ & 28 & 184 & $86.7 \%$ \\
Threshold Checks & $66.8 \%$ & 17 & 0 & $100 \%$ & 76 & 136 & $64.1 \%$ \\
\hline
\end{tabular}

- Ground Truth=17 Rain Events and 212 No Rain Events

- Successful Identification Rate (SIR) = Number of Successful Retrievals/ Number of Ground Truth

Table 4. Rain identification statistics obtained using the RF and TC techniques in 2000 .

\begin{tabular}{lcccccccc}
\hline & \multicolumn{3}{c}{ Overall } & \multicolumn{3}{c}{13 Rain Events } & \multicolumn{3}{c}{211 No Rain Events } \\
& SIR & Rain & No Rain & SIR & Rain & No Rain & SIR \\
Rain Flag (Grody) & $87.0 \%$ & 10 & 3 & $76.9 \%$ & 26 & 185 & $87.6 \%$ \\
Threshold Checks & $76.7 \%$ & 13 & 0 & $100 \%$ & 52 & 159 & $75.3 \%$ \\
\hline
\end{tabular}

-Ground Truth=13 Rain Events and 211 No Rain Events

Table 5. Rain identification statistics obtained using the RF and TC techniques in 2001 .

\begin{tabular}{lccccccc}
\hline & \multicolumn{3}{c}{ Overall } & \multicolumn{3}{c}{53 Rain Events } & \multicolumn{3}{c}{396 No Rain Events } \\
& SIR & Rain & No Rain & SIR & Rain & No Rain & SIR \\
Rain Flag (Grody) & $89.0 \%$ & 44 & 9 & $83.0 \%$ & 40 & 356 & $89.8 \%$ \\
Threshold Checks & $61.6 \%$ & 53 & 0 & $100 \%$ & 172 & 224 & $56.5 \%$ \\
\hline
\end{tabular}

- Ground Truth= 53 Rain Events and 396 No Rain Events

\subsection{Quantitative Rainfall Retrievals}

Defining the relationship between the increased Tbs and RRs for emission rainfall algorithms (or decreased Tbs and RRs for scattering rainfall algorithms) requires either utilizing theoretically derived relationships between Tbs and RRs or employing regression techniques against ground-truth data (Liu et al. 2001). This study used a piecewise linear regression technique in order to retrieve quantitative RRs. Notably, within the dynamic ranges, the relation- 
ship of RR and AMSU-A Tb originally was near linear (This study assumed the relationship between RR and AMSU-A multiple-channel Tbs in this interval to be linear). A linear relationship yields a one-to-one function, and thus the piecewise linear regression technique was used for retrieving oceanic RRs in this study. Tables 6, 7, and 8 list equations used in this study calculated using the JMA data and their coincident AMSU-A multiple-channel Tbs through a piecewise linear regression technique.

Since the emission rainfall algorithm is suitable only before the saturation point, the key point of the rainfall algorithm used in this study is to determine which AMSU-A channel can join the multiple-variable linear regression within a specific piecewise linear regression interval. Figure 2 presents the concept of piecewise linear regression for the emission rainfall algorithm. The figure was plotted using a second-order polynomial curve to simulate the increase of Tbs

Table 6. Retrieved RR obtained using the emission-based mechanism singlechannel linear regression equations from 1999 to 2001 at $23.8 \mathrm{GHz}$ and $31.4 \mathrm{GHz}$ respectively. The samples of the AMSU-A pixels used are 1929, 1454, and 3456 for 1999, 2000, and 2001 respectively.

\begin{tabular}{|c|c|c|c|c|c|c|}
\hline \multirow{2}{*}{$\begin{array}{l}\text { Emission-based mechanism } \\
\text { Single-channel Linear Regression } \\
\text { Equations } \\
\mathrm{RR}(\mathrm{mm} / \mathrm{hr}) ; \mathrm{Tb}(\mathrm{K})\end{array}$} & \multirow[t]{2}{*}{ Channel } & \multirow[t]{2}{*}{ R2 } & \multicolumn{4}{|c|}{ Maximum Retrieved Rain Rate ( $R R$ ) } \\
\hline & & & 1999 & 2000 & 2001 & minimum \\
\hline $\mathrm{RR} 23=0.231 \mathrm{~Tb} 23-51.348$ & 1 & 0.70 & 9.22 & 10.59 & 10.58 & 9.22 \\
\hline RR31 $=0.147 \mathrm{~Tb} 31-29.48$ & 2 & 0.56 & 8.86 & 9.04 & 9.20 & 8.86 \\
\hline
\end{tabular}

Table 7. Like Table 6, except for the multi-channel linear regression equatioon.

\begin{tabular}{lcccc} 
Emission-based mechanism & Channel & R2 & Maximum Retrieved Rain Rate (RR) \\
$\begin{array}{l}\text { Multi-channel Linear Regression } \\
\text { Equation }\end{array}$ & & & \\
RR (mm/hr); Tb (K) & & & RR $\leqq 8.86$ \\
\hline$R R=-38.69+0.18 T b 23-0.01 T b 31$ & 1,2 & 0.70 &
\end{tabular}

Table 8. Like Table 6, except for the scattering-based mechanism single-channel linear regression equatioon.

\begin{tabular}{lcccccc}
$\begin{array}{l}\text { Scattering-based mechanism } \\
\text { Single-channel Linear Regression } \\
\text { Equation }\end{array}$ & Channel & R2 & \multicolumn{3}{c}{ Maximum Retrieved Rain Rate (RR) } \\
RR (mm/hr); Tb (K) & & 1999 & 2000 & 2001 & minimum \\
\hline RR89-1.03Tb89+266.06 & 15 & 0.82 & 25.23 & 21.63 & 36.96 & 21.63 \\
\hline
\end{tabular}




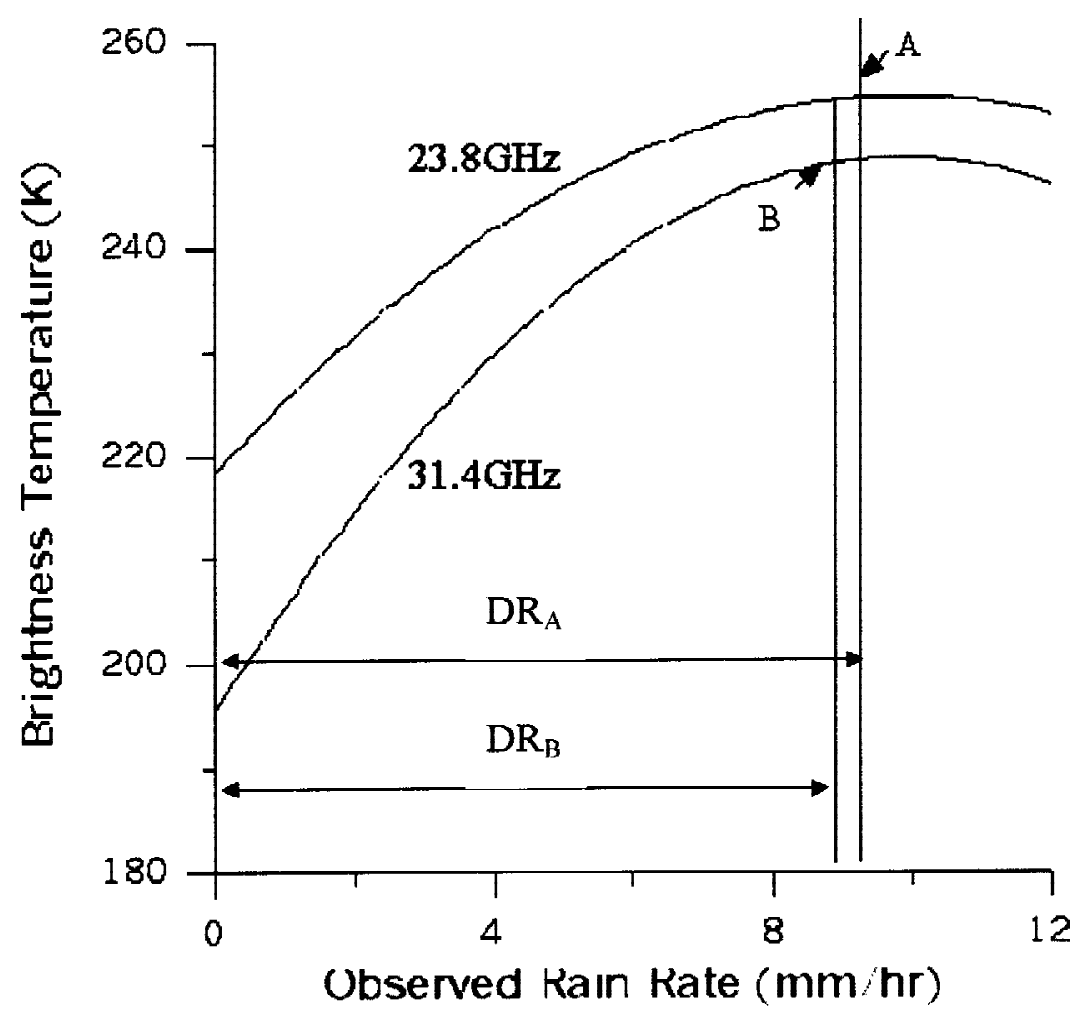

Fig. 2. Conceptual diagram shows the saturation points and dynamic ranges for the AMSU-A channels. The scatter plot of maximum rainfall saturation points is $9.22 \mathrm{~mm} \mathrm{~h}^{-1}$ (point $\mathrm{A}$ ) and $8.86 \mathrm{~mm} \mathrm{hr}^{-1}$ (point $\mathrm{B}$ ) for $23.8 \mathrm{GHz}$ and $31.4 \mathrm{GHz}$ of AMSU-A respectively.

with RRs within the dynamic range. Beyond that range, Tbs decrease with RRs. Points A and $\mathrm{B}$ denote the saturation pints at 23.8 and $31.4 \mathrm{GHz}$, and points $\mathrm{DR}_{\mathrm{A}}$ and $\mathrm{DR}_{\mathrm{B}}$ represent the dynamic ranges for 23.8 and $31.4 \mathrm{GHz}$ respectively. Within $\mathrm{DR}_{\mathrm{A}}$, only the AMSU-A channel at $23.8 \mathrm{GHz}$ can join the linear regression. Meanwhile, within $\mathrm{DR}_{\mathrm{B}}$, two AMSU-A channels of 23.8 and $31.4 \mathrm{GHz}$ can join the linear regression in this interval. To define the two-channel linear regression equation of RR and AMSU-A multiple-channel Tbs, this study restricted the domain of this equation to the interval $\left(0, \mathrm{DR}_{\mathrm{B}}\right)$. Additionally, this study restricted the domain of the two-channel linear regression equation to the interval $\left(\mathrm{DR}_{\mathrm{B}}, \mathrm{DR}_{\mathrm{A}}\right)$. Accordingly, determining of the saturation point is essential for this rainfall algorithm. The procedure for finding this cut-off point of the channel of $23.8 \mathrm{GHz}$ is described below.

The maximum retrieved RR can be obtained using all the AMSU-A data of the channel of $23.8 \mathrm{GHz}$ over the ocean as input data, and was computed using the single-channel regression equation of $23.8 \mathrm{GHz}$. The interval ranging from $0 \mathrm{~mm} \mathrm{hr}^{-1}$ to the maximum retrieved RR was assumed to be the $\mathrm{DR}_{\mathrm{A}}$ (dynamic range of channel A). Moreover, point A (Fig. 2) indi- 
cated the saturation point for the channel of $23.8 \mathrm{GHz}$ over the ocean. Since this study used satellite data for a three-year period, a maximum of three different locations of point $\mathrm{A}$ and their corresponding maximum retrieved RRs can be identified. In this study, the point with the smallest value among these three points was defined as the cut-off point. The emission rainfall algorithm is only valid within the dynamic range. In the following $23.8 \mathrm{GHz}$ channel related computations, this cut-off point should ensure that all $23.3 \mathrm{GHz}$ data remain in the dynamic range. Again, no $23.3 \mathrm{GHz}$ data beyond the saturation point was used in the computation.

In the study domain from $23^{\circ} \mathrm{N}, 124^{\circ} \mathrm{E}$ to $26^{\circ} \mathrm{N}, 126^{\circ} \mathrm{E}$, single-channel linear regression equations for the $23.8 \mathrm{GHz}$ channel were used to obtain the maximum values of oceanic RRs in 1999-2001 (Table 6). The maximum retrieved RRs for a channel at $23.8 \mathrm{GHz}$ are 9.22, 10.59 , and $10.58 \mathrm{~mm} \mathrm{hr}^{-1}$ for 1999,2000 , and 2001, respectively. The smallest value in the sample period thus is $9.22 \mathrm{~mm} \mathrm{hr}^{-1}$. As for rainfalls with an emission-based mechanism, the single-channel regression equation at $23.8 \mathrm{GHz}$ (equation RR23) was also obtained in the study domain from $23^{\circ} \mathrm{N}, 124^{\circ} \mathrm{E}$ to $26^{\circ} \mathrm{N}, 126^{\circ} \mathrm{E}$, and its coefficient of determination (Garrett and Woodworth 1960) is 0.70 . As for the $31.4 \mathrm{GHz}$ channel, its cut-off point occurred at $8.86 \mathrm{~mm} \mathrm{hr}^{-1}$, and the single-channel regression equation (RR31) was also obtained with a coefficient of determination (R2) of 0.56 . Table 7 lists the definitions of multiple-channel $(23.8 \mathrm{GHz}, 31.4 \mathrm{GHz})$ linear regression equations. In contrast, for scattering-based mechanism rainfalls, the single-channel regression equation at $89.0 \mathrm{GHz}$ (RR89) was also obtained with an R2 value of 0.82 (Table 8). Figure 3 shows the strategy of the rainfall retrieval algorithm using the AMSU-A, which is separated into two categories of rainfall retrievals to deal with the rainfall associated with emission-based or scattering-based mechanisms.

Combining the use of GMS-5 and AMSU-A data can solve the beam-filling problem, and ensure that quantitative rainfall retrievals from AMSU-A data were reasonably accurate compared to rain gauge measurements. Checking the homogeneity of the raining area for each AMSU-A pixel is straightforward. For example, Fig. 4 shows a sample of highly inhomogeneous situations for an AMSU-A pixel located on the edge of the MCSs. Although the MIYAKOJIMA rain gauge station was located within the AMSU-A pixel, no rainfall was observed at that moment. However, the rainfall retrieval results showed it was a rain pixel. In cases such as this, satellite retrieval measurements and rain gauge measurements might differ significantly. This study ignored the rain estimation of this type of pixel, and excluded it from the statistics.

\section{RESULTS}

\subsection{Quantitative Verifications}

Using a MW rainfall retrieval algorithm presented by Chen and $\mathrm{Li}$ (2002a), the Tb values of the AMSU-A channels at 23.8,31.4, and $89.0 \mathrm{GHz}$ were suitable for retrieving oceanic RRs with properly designed multiple-channel linear regression equations. This algorithm assumed that the relationship between RR and $\mathrm{Tb}$ was near linear within the dynamic range. The AMSUA multiple-channel Tbs and one-hour accumulated rainfall thus were used to establish linear 


\section{Emission-based mechanism}
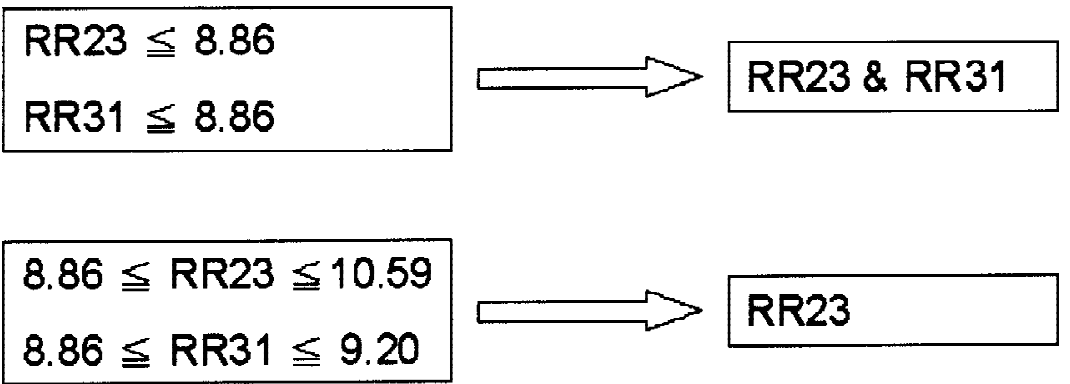

\section{Scattering-based mechanism}

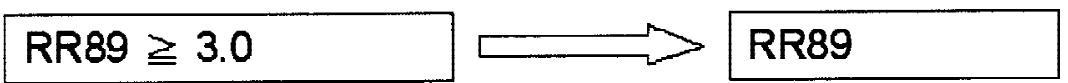

Fig. 3. Strategy of rainfall retrieval used in each linear regression interval. The whole rainfall retrieval range comprises several piecewise linear regression intervals, and is separated into two categories involving rainfall retrieval for emission-based and scattering-based mechanisms respectively.

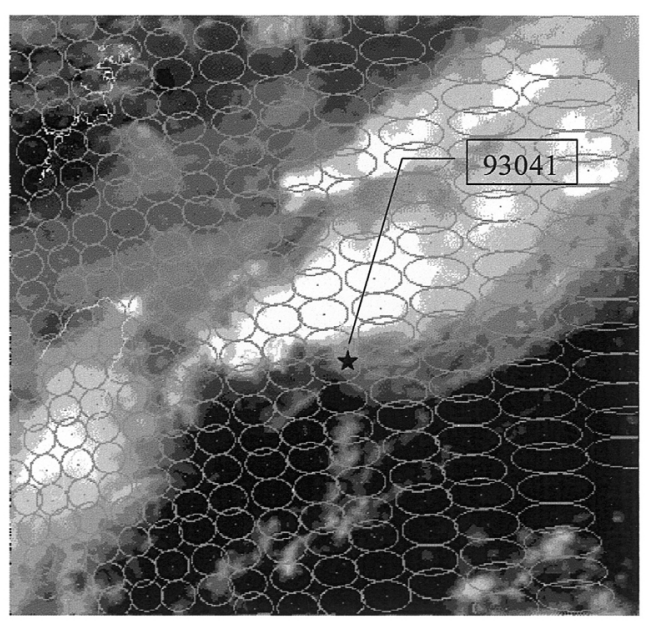

Fig. 4. The GMS-5 IR $11 \mu \mathrm{m}$ image at 0532UTC on 6 Jun 2001; the gray circle shows AMSU-A FOV at 0542UTC on 6 Jun 2001. The island rain gauge station MIYAKOJIMA (\#93041) is located on the edge of MCS and caused the beam-filling problem. 
regression equations and estimate precipitation. The retrieval results demonstrate the average RRs within AMSU-A FOV (Zhao et al. 2000).

Island rain gauge data from four JMA stations (\#94001, 94061, 94081, and 94116) were taken as the ground truth representing the average RR in quantitatively verifying the retrieval results. Considering the spatial resolution of the AMSU-A data, a corresponding Tbs/RR pair is defined based on a distance from the center of the effective field of view to the island rain gauge station of below $25 \mathrm{~km}$, and a temporal difference of below 1 hour. During the period from May to June in 1999 - 2001, 40 Tbs/RR pairs thus were classified as corresponding. Using the TC technique, the $40 \mathrm{Tbs} / \mathrm{RR}$ pairs were divided into 33 emission-based rain types and seven scattering-based rain types. Estimation of emission-based RR included two RR retrievals with RR values less than $1.5 \mathrm{~mm} \mathrm{hr}^{-1}$, and they were discarded. Within the 31 corresponding Tbs/RR pairs of emission-based rain types, the coefficient of determination (simplified with symbol "R2") was 0.76 . Moreover, the seven corresponding Tbs/RR pairs of scattering-based rain types has R2 of 0.86 . Finally, 36 of the 38 corresponding Tbs/RR pairs had intensities of less than $10 \mathrm{~mm} \mathrm{hr}^{-1}$, while the remaining two pairs had intensities of less than $20 \mathrm{~mm} \mathrm{hr}^{-1}$. Figure 5 shows the scatter plot of the estimated and observed RRs. Applying a linear regression technique through the origin, the R2 was calculated as 0.72 $(\mathrm{Re}=1.38 \times \mathrm{RRo})$. This clearly shows an overestimation of the $\mathrm{RRe}$ (Rain Rate of Estimation) compared to the RRo (Rain Rate of Observation). The estimated RR over the ocean obtained through the above approach is almost the same as that obtained by Goldberg (1999).

This study also performed an independent test using an independent data set gathered from islands away from the four JMA stations. Figure 6 shows the quantitative verification results with an $\mathrm{R} 2$ value of 0.5 . This data was provided independently from the Pengchiayu $\left(25.62^{\circ} \mathrm{N}, 122.07^{\circ} \mathrm{E}\right)$, Lutao $\left(22.65^{\circ} \mathrm{N}, 121.47^{\circ} \mathrm{E}\right)$, and Lanyu $\left(22.04^{\circ} \mathrm{N}, 121.55^{\circ} \mathrm{E}\right)$. Forty $\mathrm{Tbs} / \mathrm{RR}$ pairs occurred during the same period, and had RR retrievals of less than $10 \mathrm{~mm} \mathrm{hr}^{-1}$. Among the $40 \mathrm{Tbs} / \mathrm{RR}$ pairs, seven RR retrievals for the $40 \mathrm{Tbs} / \mathrm{RR}$ pairs were under $0 \mathrm{~mm} \mathrm{hr}^{-1}$. Results showed that the rainfall algorithm developed for the area near Japan required slightly modification to make it suitable for application elsewhere.

\subsection{Qualitative Verification}

Limited MW remote sensing technology, a poor temporal scan resolution strategy, and a narrow scan-swath restrict the application of a single-satellite rainfall observation system in both flash flood watching and heavy oceanic rainfall warnings. Using a rainfall algorithm (Chen and Li 2002a), this study presented an oceanic RR retrieval using the Tropical Rainfall Measuring Mission (TRMM) Microwave Imager (TMI) for quantitative comparison, with the RR retrieval using the AMSU-A. When the AMSU-A's observations were unavailable, RR retrievals were made using the IR data from the GMS-5 (Chen and Li 2002b) or using MW data from the TMI for continuous monitoring of this MCS. The essential task in this is to eliminate the discrepancy between different rainfall algorithms.

During the Green Island Mesoscale Meteorological Experiment (GIMEX), the IR image of the $11 \mu \mathrm{m}$ band of VISSR/GMS-5 was used to observe MCSs prevailing over the South China Sea. At 0532 UTC on 23 May 2001, the GMS-5/VISSR observed an MCS to the east of 


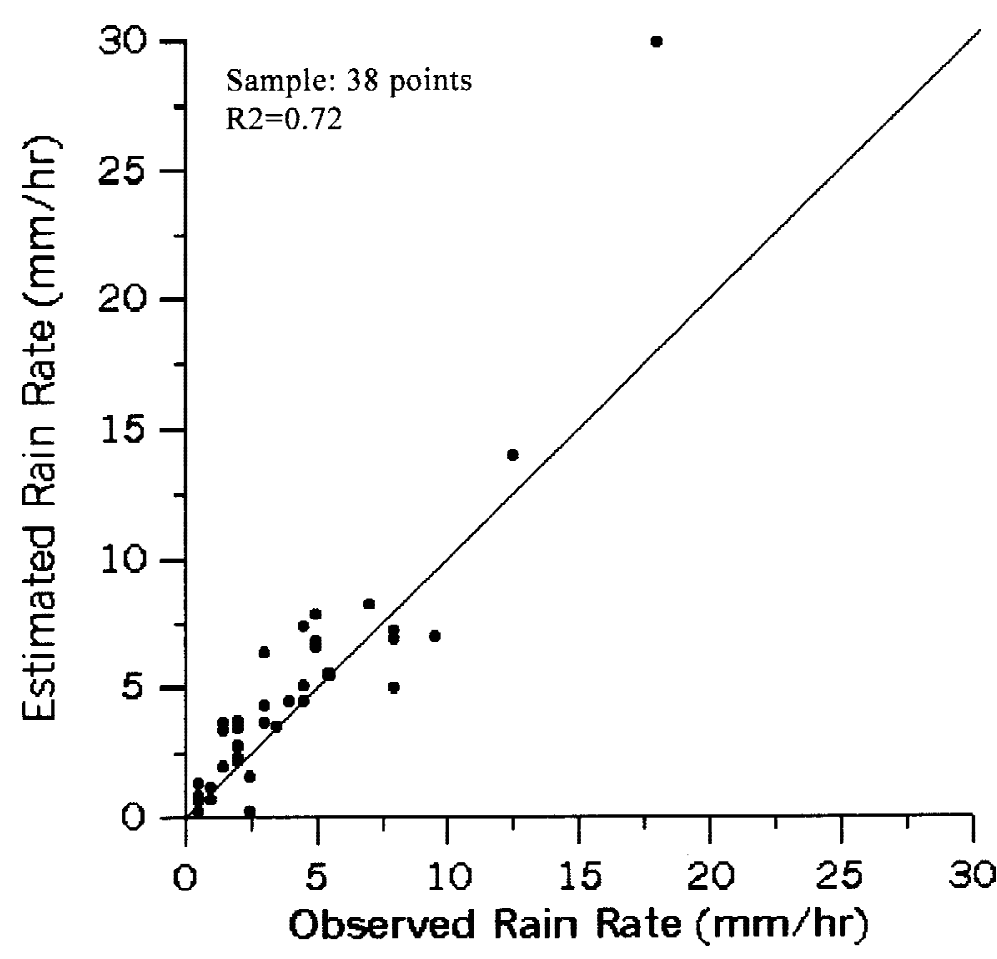

Fig. 5. Scatter plot of AMSU-A RR retrievals and observed RRs showing the quantitative verification results. Hourly island gauge data from four island station numbers $94001,94061,94081$, and 94116 were used as ground-based validation data. Applying a linear regression technique through origin finds a coefficient of determination of 0.72 .

Hong Kong (Fig. 7). Cloud-tops with low IR $11 \mu \mathrm{m}$ Tbs $(\leq 210 \mathrm{~K})$ were spread from $19^{\circ} \mathrm{N}$ to $21^{\circ} \mathrm{N}$. Figure 8 shows oceanic RR retrievals using the TMI (orbit \#20064) at 0534UTC on 23 May 2001. Corresponding rain identification results were made using the TC technique, and three regions had RRs exceeding $10 \mathrm{~mm} \mathrm{hr}^{-1}$. The maximum RR values retrieved within these three regions were $40 \mathrm{~mm} \mathrm{hr}^{-1}\left(19.9^{\circ} \mathrm{N}, 113.5^{\circ} \mathrm{E}\right), 32.5 \mathrm{~mm} \mathrm{hr}^{-1}\left(19.0^{\circ} \mathrm{N}, 114.5^{\circ} \mathrm{E}\right)$, and $21.4 \mathrm{~mm} \mathrm{hr}^{-1}$ $\left(19.9^{\circ} \mathrm{N}, 117.1^{\circ} \mathrm{E}\right)$, respectively. Rain regions existed over an area ranging from $17^{\circ} \mathrm{N}, 112^{\circ} \mathrm{E}$ to $21.8^{\circ} \mathrm{N}, 120^{\circ} \mathrm{E}$. All MCS rainfalls were classified into scattering-based mechanisms and emission-based mechanisms using the TC technique. Results show that the rain regions generally were located between $18.5^{\circ} \mathrm{N}$ and $21^{\circ} \mathrm{N}$, conforming reasonably well to the pattern of the cold cloud-tops.

Figure 9 shows oceanic RR retrievals using the AMSU-A data at 0626UTC on 23 May 2001. The figure reveals two regions with RRs exceeding $10 \mathrm{~mm} \mathrm{hr}^{-1}$. The heaviest $\mathrm{RR}$ (located at $19.7^{\circ} \mathrm{N}, 113.8^{\circ} \mathrm{E}$ ) had a value of $26.5 \mathrm{~mm} \mathrm{hr}^{-1}$, while the other (located at $20.8^{\circ} \mathrm{N}, 117.4^{\circ} \mathrm{E}$ ) had a value of $13.5 \mathrm{~mm} \mathrm{hr}^{-1}$. Within the GMS-5 IR image, the IR Tbs observed in both heavy 


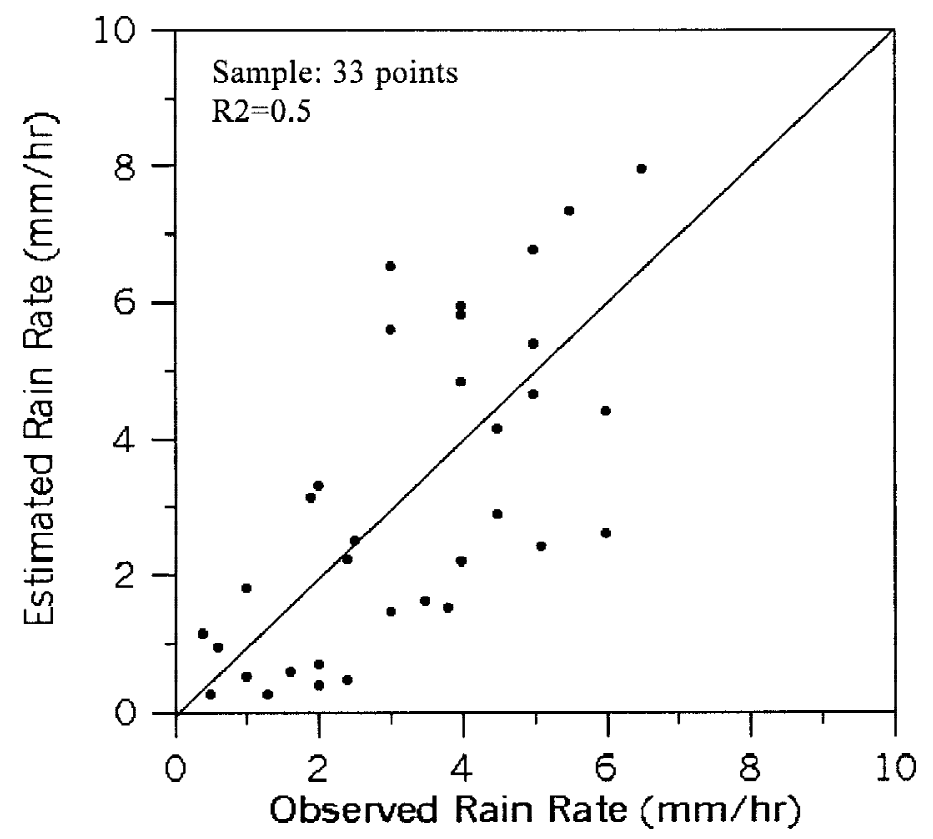

Fig. 6. A scatter plot of AMSU-A RR retrievals and observed RRs of from the three islands namely Pengchiayu $\left(25.62^{\circ} \mathrm{N}, 122.07^{\circ} \mathrm{E}\right)$, Lutao $\left(22.65^{\circ} \mathrm{N}\right.$, $\left.121.47^{\circ} \mathrm{E}\right)$, Lanyu $\left(22.04^{\circ} \mathrm{N}, 121.55^{\circ} \mathrm{E}\right)$, showing the quantitative verification results. The $\mathrm{R} 2$ is 0.5 .

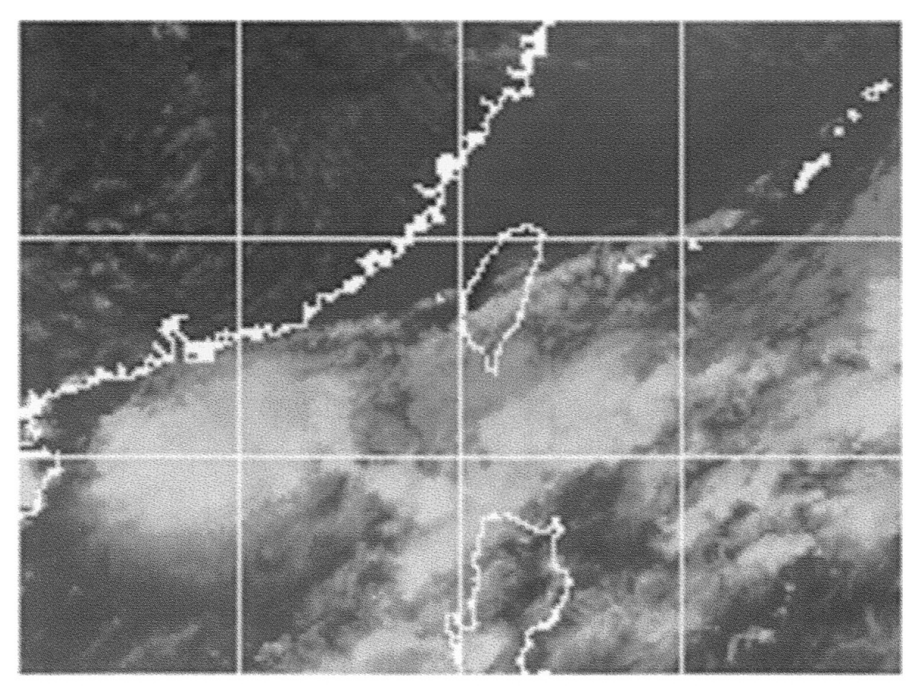

Fig. 7. GMS-5 IR $11 \mu \mathrm{m}$ image at 0532UTC on 23 May 2001. 


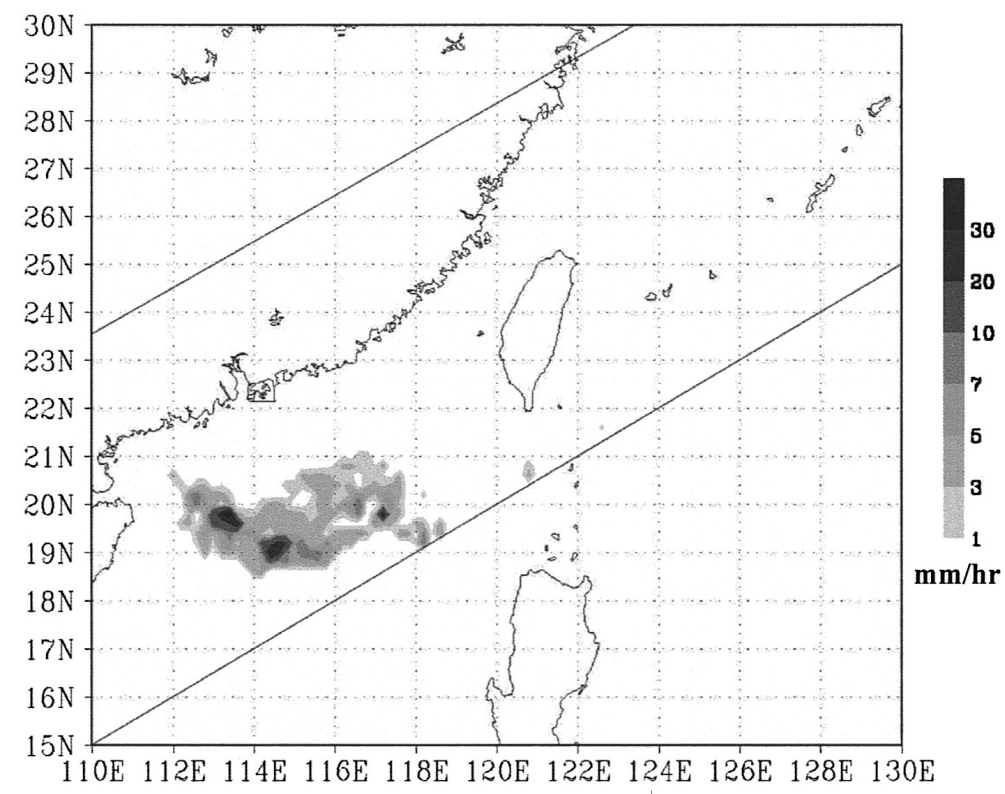

Fig. 8. TMI RR retrievals at 0534UTC on 23 May 2001.

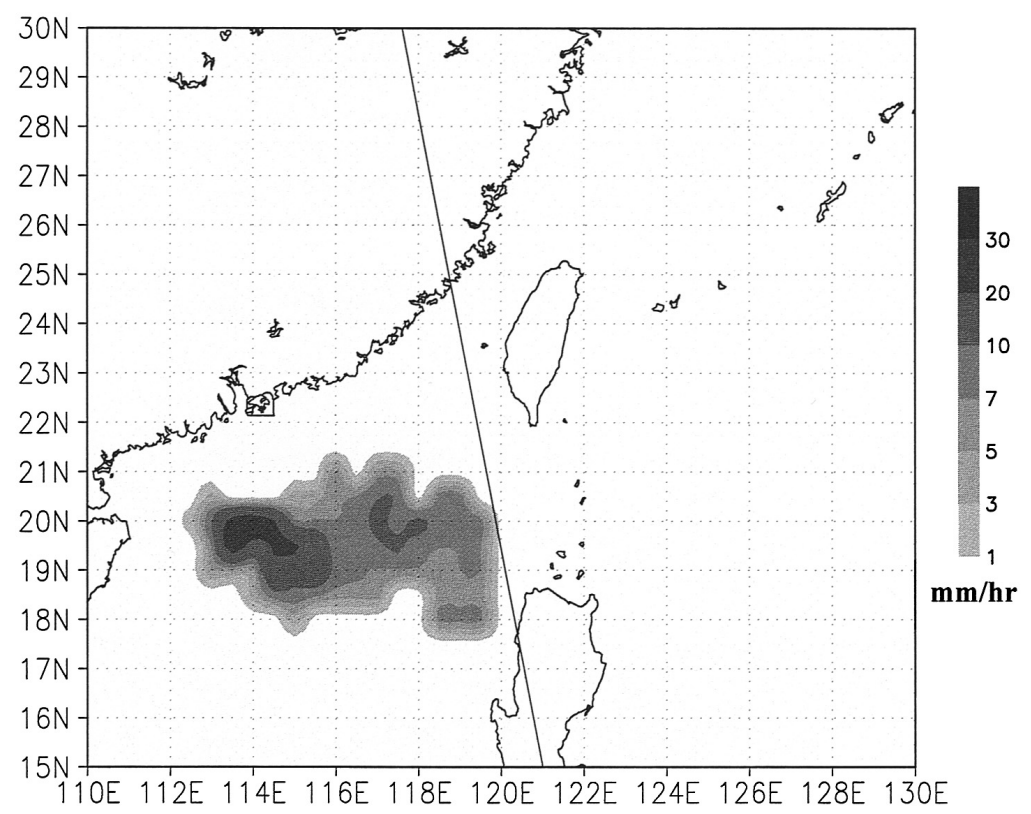

Fig. 9. AMSU-A RR retrievals at 0626UTC on 23 May 2001. 
rainfall regions ranged from $200 \mathrm{~K}$ to $210 \mathrm{~K}$. Thus, compared with Fig. 7, the rain regions and heavy rainfall displayed very similar patterns. However, AMSU-A RRs (Fig. 9) were less than those of TMI RRs (Figs. 8). The reason for this phenomenon may be that TMI has better resolution than AMSU-A. Moreover, if the AMSU-A RRs were multiplied by a factor of approximately 1.5, their intensities were roughly equal to those of the TMI RRs. This was especially true for heavy rainfalls. Therefore, an oceanic MCS can be monitored more frequently using a multiple-satellite rainfall observation system than by using a single-satellite system. The AMSU-A data can be obtained one hour after the NOAA satellite passes over Taiwan, and this near real-time data transferal is very helpful for preventing major disasters. Figure 10 shows a good agreement in qualitative comparisons among the TMI RR, AMSU-A RR, and TRMM Algorithm 2A12-TMI RR (NASA RR) provided by the TRMM Data and Information System. Notably, algorithm 2A12 is based on a Bayesian approach, resembling that developed by Kummerow et al. (1996).

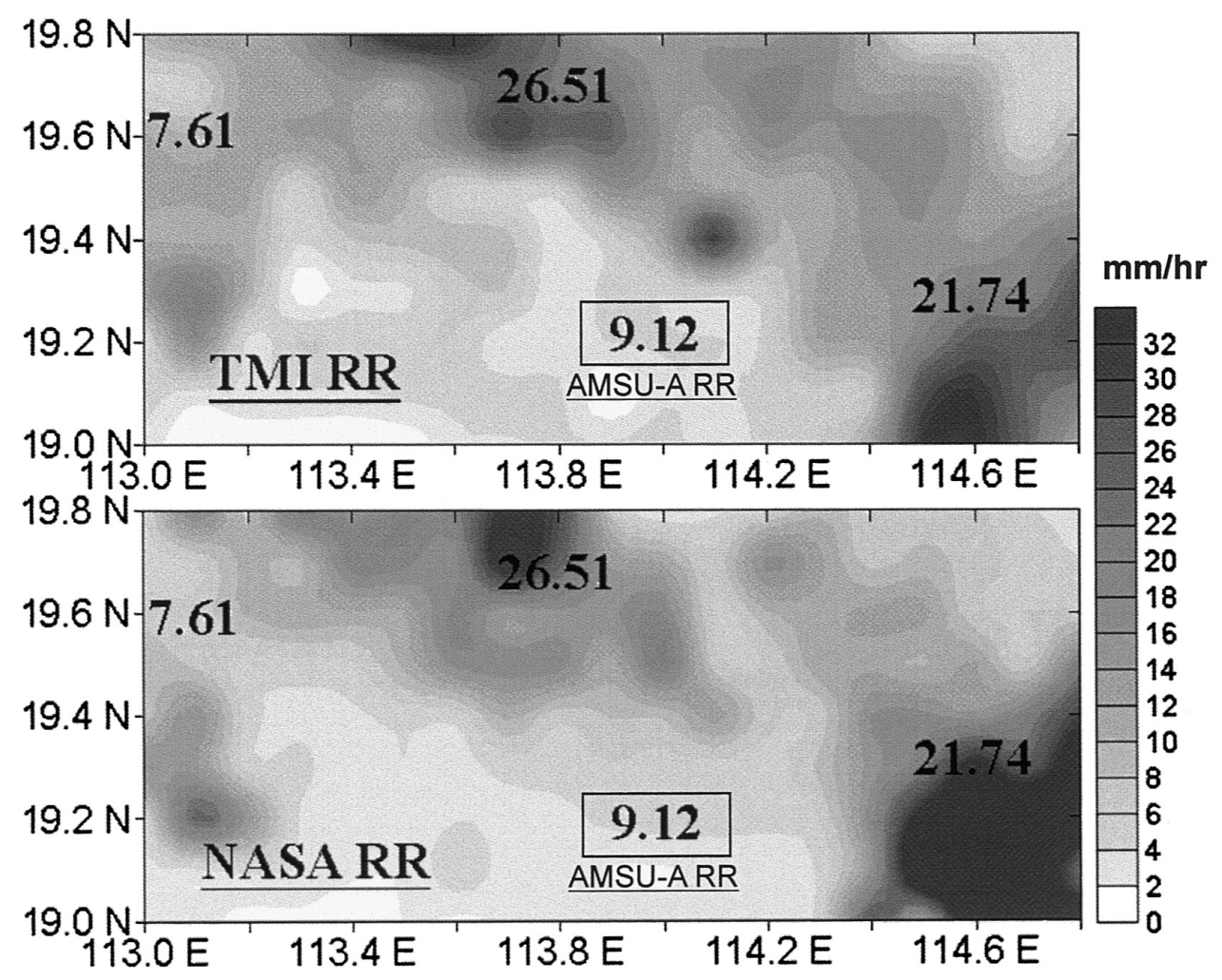

Fig. 10. Comparison of retrieval rainfalls among TMI RR, AMSU-A RR and TRMM Algorithm 2A12-TMI RR (NASA RR) at 0626UTC (for AMSUA) and at 0534UTC (for TMI) on 23 May 2001. 


\section{CONCLUSIONS}

This study developed an oceanic rainfall algorithm using the AMSU-A channels at 23.8, 31.4 , and $89.0 \mathrm{GHz}$. Validation of rain identification was carried out using rain gauge data that showed that the overall successful recognition rate exceeded $87 \%$. As for quantitative validation, the coefficient of determination is 0.72 . The algorithm developed in this study was shown to be suitable for retrieving the rainfall rate at sea. Additionally, the algorithm developed here also can provide a useful comparison with the modeling results.

The existing individual microwave radiometer currently cannot provide enough measurements to monitor MCSs occurring at sea, so the best policy is to use multi- microwave channels on board different platforms, to obtain rainfall rate. Inter-calibration between the rainfall rates should be performed before combining the rain retrievals from various satellite radiometers. Since the study results showed good agreement in qualitative comparisons among TMI RR, AMSU-A RR, and TRMM Algorithm 2A12-TMI RR, and since the intensities of AMSU-A RRs roughly equaled those of the TMI RRs when multiplied by a factor of approximately 1.5 (especially true for heavy rainfalls), good potential exists for establishing a dual-satellite rainfall observation system using both AMSU-A and TMI instruments. In the future the Precipitation Radar instrument is expected to be included in the observation system.

Additionally, the use of real-time data from the AMSU-A should yield better quantitative predictions of heavy rainfall and new knowledge in the study of the MCSs. The results presented in this study also showed that the optimal advantage of this statistical approach is the simplicity of the calculations involved. Further improvements in this algorithm would be helpful for accurately estimating rainfall rates over ocean areas.

Acknowledgements The authors gratefully thank Dr. Fuzhong Weng at NOAA/NESDIS and two anonymous reviewers for providing helpful comments and suggestions on the manuscript. The staff of EUMETSAT is appreciated for providing the ATOVS and AVHRR Processing Package (AAPP V3.0) and also for their help in reading AMSU-A data. Special appreciation is extended to the NOAA Satellite Active Archive System office of the US for providing AMSU-A Level_1B data free of charge. Moreover, the Central Weather Bureau of Taiwan is appreciated for providing the surface rain gauge and GMS-5 data during the period of the GIMEX. This study was supported by the National Science Council of the R.O.C., under grants NSC91-2111-M-014-005 and NSC91-2625-Z-014-002.

\section{REFENERCES}

Chen, W. J., and C. C. Li, 2000: Oceanic rain rate retrievals using TRMM Microwave Imager multi-channel brightness temperatures during the 1998 SCSMEX.Terr. Atmos. Ocean. Sci., 11, 765-788.

Chen, W. J., and C. C. Li, 2002a: An infrared rainfall algorithm for the MCSs prevailing over the South China Sea during the Mei-Yu season. Terr. Atmos. Ocean. Sci., 13, 65-90. 
Chen, W. J., and C. C. Li, 2002b: Rainfall retrievals using Tropical Rainfall Measuring Mission and Geostationary Meteorological Satellite 5 data obtained during the SCSMEX. Inter. J. Remo. Sens., 23, 2425-2448.

Garrett, H. E., and R. S. Woodworth, 1960: Statistics in phychology and education. Longmans, Green and Co., 478pp.

Goldberg, M. D., 1999: Generation of Retrieval Products from AMSU-A: Methodology and Validation. Proc. $10^{\text {th }}$ Int. TOVS Study Conf. Boulder, CO., USA.

GMS-5 User's Guide, 1997: Meteorological Satellite Center of Japan, Nakakiyoto, Kiyose, Tokyo, 190pp.

Grody, N. C., F. Weng, and R. R. Ferraro, 1999: Application of AMSU for Obtaining Hydrological Parameters, Microwave Radiometry and Remote Sensing of the Earth's Surface and Atmosphere. VNU Science Press, Brill Academic Publishers, Inc., 339-351.

Kummerow, C., W. S. Olson, and L. Giglio., 1996: A Simplified Scheme for Obtaining Precipitation and Vertical Hydrometeor Profiles from Passive Microwave Sensors. IEEE Trans. Geosci. Remote Sens., 34, 1213-1232.

Kummerow C., 1998: Beam-filling errors in passive microwave rainfall retrievals.J. Appl. Meteor., 37, 356-370.

Liu, G. R., C. C. Liu, and T. H. Kuo, 2001: Rainfall intensity estimation by ground-based dual-frequency microwave radiometers. J. Appl. Meteor., 40, 1035-1041.

Richards, J. A., and X. Jia, 1999: Remote Sensing Digital Image Analysis- An Introduction. Springer, $363 \mathrm{pp}$.

Weng, F., L. Zhao, R. F. Ferraro, G. Poe, X. Li, and N. C. Grody, 2003: Advanced microwave sounding unit cloud and precipitation algorithms. Radio Sci., 38, 1-13.

Wilheit, T. T., and A. T. C. Chang, 1980: An algorithm for retrieval of ocean surface and atmospheric parameters from the observations of the scanning multi-channel microwave radiometer. Radio Sci., 15, 525-544.

Zhao, L., R. R. Ferraro, and D. Moore, 2000: Validation of NOAA-15 AMSU-A Rain Rate Algorithms. Proc. $10^{\text {th }}$ Conf. Satellite Meteor. Oceanogr., Long Beach, CA, January 9$14,3.5 \mathrm{pp}$. 